\title{
EMPREENDEDORISMO FEMININO NO BRASIL: TEORIAS, POLÍTICAS E TENDÊNCIAS
}

\section{FEMALE ENTREPRENEURSHIP IN BRAZIL: THEORY, POLICIES AND TRENDS}

Recebido em 27.10.2018. Aprovado em 21.12.2018

Avaliado pelo sistema double blind review

Juliana Soares da Silva

Universidade Federal de Roraima - Campo Grande - MS

julianas@outlook.com

Michel Frank Sullivan dos Santos Tavares

Universidade Federal de Roraima - Campo Grande - MS

supervisormichel@gmail.com

Djanires Lageano Neto de Jesus

Universidade Federal de Roraima - Campo Grande - MS

netoms@unigran.br

\section{Higya Alessandra Merlin}

Universidade Federal de Roraima - Campo Grande - MS

higya.merlin@unigran.br

\begin{abstract}
Resumo
Neste estudo, pretendeu-se esboçar as principais contribuições teóricas nacionais relativas ao empreendedorismo feminino, inserindo-as na perspectiva da realidade verificada pelos números e por estudos de nível mundial, que apontam algumas tendências e perspectivas sobre o tema. A partir disso, foi construída uma breve análise de como está o movimento empreendedor feminino no Brasil. Para dar conta do proposto, realizou-se um levantamento bibliográfico e documental de importantes perspectivas mundiais. Até que se chegasse aos dados do caso brasileiro, percorreu-se uma análise teórica dos principais e recentes estudos sobre o tema no Brasil. Foram utilizadas, também, algumas pesquisas comparadas a outros países, bem como um breve relato das principais ações de apoio ao empreendedorismo feminino. Por fim, com uma análise exploratória de dados, foram traçadas algumas tendências e aplicações das teorias verificadas com base nos dados postos. 0 presente trabalho está estruturado em seis seções, a saber: introdução; empreendedorismo feminino no mundo, na América Latina e no Brasil; perspectivas atuais e contribuições teóricas no Brasil; políticas e programas de apoio; tendências e rumos; conclusão. Por resultados, verificou-se que o empreendedorismo no Brasil enfrenta fortes desigualdades, porém é sustentado pela força empreendedora da mulher brasileira, força esta que merece novos estudos, para que o cenário seja melhor exposto e delineado.
\end{abstract}

Palavras-chaves: Desigualdades de Gênero; Mulheres Empreendedoras; Gestão Feminina.. 


\begin{abstract}
This study aimed to outline the main national theoretical contributions regarding female entrepreneurship, inserting them in the perspective of the reality verified by the numbers and world-wide studies, which point out some tendencies and perspectives on the subject. From this, a brief analysis of how the female entrepreneurial movement in Brazil was constructed. In order to give an account of the proposal, a bibliographical and documentary survey of important world perspectives was carried out. Until the data of the Brazilian case were arrived at, a theoretical analysis of the main and recent studies on the subject in Brazil was followed. We also used some research compared to other countries, as well as a brief report on the main actions to support female entrepreneurship. Finally, with an exploratory analysis of data, some tendencies and applications of the theories verified based on the data put were traced. The present work is structured in six sections, namely: introduction; women entrepreneurship in the world, in Latin America and in Brazil; current perspectives and theoretical contributions in Brazil; policies and programs; trends and directions; conclusion. As a result, it was verified that entrepreneurship in Brazil faces strong inequalities, but it is supported by the entrepreneurial force of Brazilian women, a force that deserves further studies, so that the scenario is better delineated and exposed.
\end{abstract}

Keywords: Gender Inequalities. Women Entrepreneurs. Women's Management.

\title{
Introdução
}

$O$ combate à desigualdade de gênero tem-se tornado um tema frequentemente tratado entre as conferências internacionais, iniciando o diálogo para a imposição e prática da transversalidade do gênero, seja em âmbito nacional, estadual ou municipal. Nessa iniciativa, o Brasil tem fortalecido e criado nos últimos anos políticas públicas que visam à inserção do público feminino de forma igualitária no mercado de trabalho, bem como o acesso à educação e à saúde, o combate à violência contra mulher, e, principalmente, a informação quanto aos seus direitos (CEPAL, 2013).

Diante dessas perspectivas institucionais, a questão do empreendedorismo feminino tem seu destaque, configurando-se como um meio alternativo ao mercado de trabalho, pois, neste ambiente, as disparidades de gênero são acentuadas, assim como a baixa remuneração da mulher e a maior carga horária de trabalho (SEBRAE, 2013; 2015). Assim, a prática de empreender vem se tornando cada vez mais forte entre o público feminino, com destaque para as atividades de comércio e serviços, relativas ao segmento de beleza, alimentício e de vestuário (GEM, 2016).

Para a gestão desses novos empreendimentos, as empreendedoras buscam apoio em órgãos públicos, principalmente no sistema "S" brasileiro. Esse interesse em melhorar o seu negócio sofre, em certa medida, influência do maior grau de instrução do gênero feminino adquirido nos últimos anos (GEM, 2016).

Dessa maneira, o presente trabalho parte do seguinte questionamento: as disparidades entre homens e mulheres têm sido dirimidas diante do avanço da inserção da mulher no mercado de trabalho e no empreendedorismo no Brasil? Buscando responder a este questionamento, o objetivo deste trabalho deuse em construir um cenário analítico sobre o empreendedorismo feminino no Brasil a partir de três objetivos específicos, a saber: analisar as principais contribuições teóricas nacionais relativas ao empreendedorismo feminino; inserir as teorias verificadas em uma perspectiva da realidade demonstrada pelos números e por estudos de nível mundial, que apontam algumas tendências e perspectivas sobre o tema; realizar um resgate das políticas e ações em prol do empreendedorismo feminino.

Quanto ao procedimento metodológico, a pesquisa apresenta-se como bibliográfica e documental. Conforme Gil (2008), esse tipo de pesquisa caracteriza-se pela utilização de relatórios, livros, artigos e outras pesquisas, dando, assim, a possibilidade de uma cobertura mais geral e de evolução do tema tratado, conforme a pretensão apresentada no objetivo. Quanto ao nível, a pesquisa caracteriza-se como exploratória e descritiva. Apresenta-se, também, uma análise exploratória de dados secundários, que se 


\section{Juliana Soares da Silva, Michel Frank Sullivan dos Santos Tavares, Djanires Lageano Neto de Jesus, Higya Alessandra Merlin}

constitui pela reapresentação gráfica de dados já previamente coletados e tabulados, conforme ponderam Anderson, Sweeney e Williams(2002).

$\mathrm{O}$ trabalho está dividido em seis seções. Após esta breve introdução, que corresponde à primeira seção, segue a contextualização do empreendedorismo feminino no mundo, com ênfase na América Latina e no Brasil. A terceira seção apresenta algumas perspectivas e leituras teóricas sobre o empreender feminino brasileiro. A quarta seção descreve as políticas públicas voltadas para as mulheres. Ato contínuo, na quinta seção, são apresentadas as tendências e os rumos sobre o tema, confluindo para as considerações finais, correspondentes à sexta seção.

\section{Empreendedorismo feminino no mundo, na América Latina e no Brasil}

Um estudo do Word EconomicForum (WEF) do ano de 2005, que avaliou o empoderamento feminino e as disparidades ocorridas neste processo em 58 países, revelou que o Brasil ocupa a quinquagésima primeira posição no ranking mundial, com o seu pior indicador sendo a oportunidade econômica ao gênero feminino. O estudo em questão avaliou cinco dimensões, sendo elas a participação econômica, a oportunidade econômica, o empoderamento político, os avanços educacionais e a saúde e o bem-estar.

O supracitado estudo destacou, ainda, pontos importantes como o fato de que nem mesmo os países nórdicos conseguiram superar as disparidades de gênero existentes, embora tenham obtido uma redução significativa. Outro ponto de destaque refere-se à realidade econômica globalizada, na qual países que deixam de alocar adequadamente metade de seu contingente de mão de obra estão incorrendo em grave erro estratégico. Os países que ocupam as três primeiras posições no ranking do estudo são: Suécia, Noruega e Islândia, respectivamente.

$O$ índice de empreendedorismo feminino Female Enterpreneurship Index (FEI), calculado pelo The Global Enterpreneurship and Development Institute (GEDI) no ano de 2015, para 77 países, incluiu as características individuais e institucionais que podem potencializar ou inibir o empreendedorismo feminino nestes países, como ambiente legal, normas, valores e a capacidade de iniciação de novos negócios. Dos 77 países analisados, apenas 16 apresentaram índices considerados altos.

A partir da Figura 1, é possível ter uma noção geográfica do tema tratado. Um olhar rápido permite perceber que parte significativa da Europa, Estados Unidos e a Austrália são as regiões em que países despontam com relação às boas condições e ao bom potencial do empreendedorismo feminino. Já os países do continente Africano, da América Latina e a Rússia apresentam scores menos positivos para 0 empreendedorismo feminino, sinalizando caminhos mais difíceis, ambiente empreendedor menos favorável e desigualdades mais intensas que nos países e regiões anteriormente citados. 


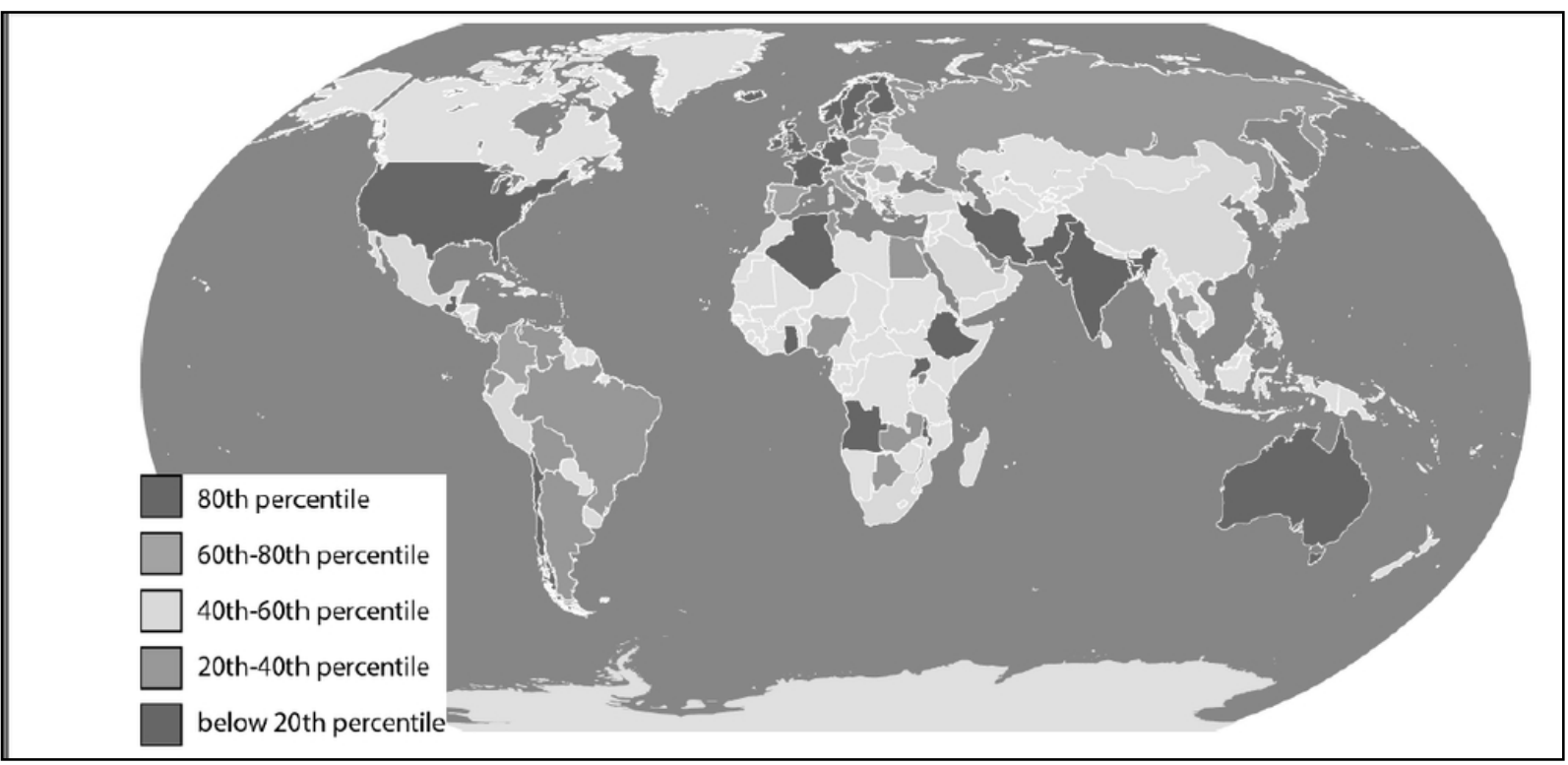

Figura 1: Índice de empreendedorismo feminino para 77 países selecionados.

Fonte: GEDI - The 2015 FemaleEnterpreneurship Index.

Em um breve comparativo entre o FEl e o Global Entrepreneurship Index (GEI), nota-se que os países da Europa Oriental possuem índices melhores de empreendedorismo feminino, o que demonstra que estes países são melhores apoiadores deste tipo específico de empreendedores do que do empreendedorismo em geral. $O$ oposto é verificado no Leste Asiático, onde, dentre os países analisados, as piores desigualdades verificadas no que tange ao empreendedorismo feminino encontram-se em Taiwan, Turquia e Arábia Saudita. Jamaica, Peru e México, por sua vez, apresentam boas posições no FEl quando comparados ao GEl.

O recente relatório de 2013 da CEPAL, alusivo à XII Conferência Regional sobre a Mulher da América Latina e do Caribe, expõe a situação de vulnerabilidade da mulher em vários aspectos. O cenário exibe que 50,9\% da população da América Latina e do Caribe, o que corresponde a cerca de 300 milhões de pessoas, são mulheres. A taxa de desemprego é de 7,9\% para as mulheres e de 5,6\% para os homens, sendo que as mulheres estão alocadas em maior proporção no serviço doméstico (10,7\%), contra apenas $0,05 \%$ dos homens, já que estes encontram-se em maior proporção no trabalho assalariado.

Do total de mulheres ocupadas na América Latina, 44,6\% encontram-se no setor de serviços domésticos, sendo que apenas uma em cada dez mulheres trabalha na agricultura. Ao analisar as disparidades entre a cidade e o campo, o relatório revela que a proporção de mulheres sem renda própria na cidade é de $30,4 \%$, enquanto no campo este número chega a $41,4 \%$, equivalendo as mulheres do campo a cerca de $9,9 \%$ da população total, o que implica relacionar que aproximadamente 29,7 milhões de mulheres encontram-se nesta situação (CEPAL, 2013).

O Brasil tem verificado nos últimos dois anos um forte avanço do empreendedorismo, consoante dados de pesquisa realizada em 2017 pelo Global Entrepreneurship Monitor (GEM). Os anos de 2015 e 2016 apresentaram os maiores valores da série histórica da taxa total de empreendedores, que representa 0 percentual da população entre 18 e 64 anos de idade com envolvimento em alguma atividade empreendedora.

Conforme esta mesma pesquisa, no Brasil a taxa de empreendedorismo inicial feminino é de $19,9 \%$, superando a taxa de empreendedorismo inicial masculino, que é de 19,2\%. A pesquisa expõe que Brasil e México são destaques mundiais no empreendedorismo feminino, quando confrontados aos países 


\section{Juliana Soares da Silva, Michel Frank Sullivan dos Santos Tavares, Djanires Lageano Neto de Jesus, Higya Alessandra Merlin}

analisados na pesquisa. No entanto, quando se trata de empreendimentos estabelecidos com mais de 42 meses, os homens possuem larga participação quando comparados ao gênero feminino. A taxa de empreendedorismo estabelecido é de $19,6 \%$ no tocante ao gênero masculino, e 14,3\% ao feminino, o que representa uma diferença de 5,3 pontos percentuais. Outra importante característica verificada em relação a esta pesquisa é que, dos empreendedores que buscaram apoio, 60,1\% eram mulheres.

Quanto à análise das principais atividades econômicas em que as mulheres ingressam ao empreender ou dos negócios já estabelecidos, verifica-se a predominância de restaurantes e outros serviços de alimentação e bebida, serviços domésticos e cabeleireiros, além de outras atividades de tratamento e beleza (GEM, 2017).

Sobre o ambiente empreendedor de forma geral, os fatores considerados como principais limitantes para se empreender no Brasil foram as políticas governamentais, o apoio financeiro, a educação e a capacitação, as características da força de trabalho e as normas culturais e sociais. Conforme a análise apresentada, verifica-se que países que compõem o conjunto econômico BRICS (Brasil, Rússia, Índia, China e África do Sul) são impulsionados, em sua maioria, por eficiência, enfrentando dificuldades semelhantes no ambiente empreendedor, enquanto nos países impulsionados pela inovação essas dificuldades encontram-se atenuadas, exceto pelo apoio financeiro (GEM, 2017).

\section{Perspectivas atuais e contribuições teóricas no Brasil}

Devido ao forte avanço verificado no empreendedorismo feminino, e também na entrada da mulher no mercado de trabalho, cada vez mais temas de pesquisa vêm surgindo com o propósito de apurar como se desdobram esses processos. Essas pesquisas abrangem os mais diversos aspectos, desde as motivações que têm levado as mulheres a abrirem empresas até as disparidades por elas enfrentadas para inserção no mercado empresarial e de trabalho.

Torna-se, portanto, relevante para as finalidades deste estudo observar como têm avançado as contribuições dessas pesquisas, no sentido de promover a inserção ou de alertar as mulheres e a sociedade de forma geral para temáticas delicadas que são postas à mulher no processo de empreender. Por ser vasta a gama de trabalhos, optou-se por um grupo de publicações que fazem jus ao tema em voga, com predominância nacional.

Os motivos que levam as mulheres a empreender correspondem a um tema com grande destaque na literatura. Existem diversos trabalhos da literatura internacional, como os de Still e Timms (1998), Mallon e Cohen (2001) e Martinho (2012), destacando aspectos como a falta de melhores opções de trabalho, dificuldades de ascensão na carreira profissional, necessidade ou mesmo a verificação de oportunidades de mercado, como os principais aspectos que têm levado a mulher ao empreendedorismo.

Em um estudo realizado com 90 empreendedores do Brasil, Canadá e França, Machado, StCyr e Alves (2003) verificaram que a principal razão que motivou essas mulheres a empreender foi a realização pessoal. Subscrita a esta resposta, a insatisfação com a ocupação que exerciam antes de empreender. No geral, por se tratar de mulheres com elevado grau de instrução e experiência, a visão de oportunidade no mercado foi o que orientou a sua entrada como empreendedoras. Quanto às fontes de financiamento, o estudo apontou como maioria a origem própria.

As conclusões de Martinho (2012) apontam no mesmo sentido, destacando que em Portugal, para o grupo analisado, as mulheres apresentaram exposição a uma atividade empreendedora por oportunidade, principalmente pela busca de melhores alternativas de trabalho. Outro ponto comumente estudado e intimamente relacionado com as motivações que conduzem as mulheres ao empreendedorismo é o perfil empreendedor dessas mulheres.

Por meio da aplicação da técnica Big Five Personality Model Methodology, em uma análise exploratória e descritiva, Martins et al. (2010, p.5) sintetizam que "[...] a determinação para perseguir objetivos, alcançar 
metas e superar dificuldades" é uma característica comum dos casos analisados. O perfil empreendedor exige que a mulher some habilidades de convívio em ambientes de pressão ligados à racionalidade e à agregação de pessoas em torno de um resultado e ao papel histórico da mulher na sociedade.

Sob outro ponto de vista, porém ainda na análise de perfil, Salomão (2011) propõe evidências sobre os estilos de aprendizagem e liderança das empreendedoras femininas em pequenos negócios. Esta pesquisa revelou que dois estilos de aprendizagem foram os mais comuns entre as 63 empreendedoras entrevistadas, o estilo acomodador e o divergente. Já com relação à liderança, o estilo predominante foi o transformacional. Essas características, de modo geral, estão relacionadas à lida com pessoas no processo de aprendizagem e à liderança direcionada as relações interpessoais"

A trajetória de inserção da mulher no mercado de trabalho e no empreendedorismo é marcada por uma série de lutas. Nesse contexto, buscar entender quais são os medos, as preocupações, satisfações e insatisfações das empreendedoras femininas faz muito sentido. $O$ trabalho de Jonathan (2005) posiciona a pesquisa do empreendedorismo feminino sob este enfoque.

Ao observar uma amostra de conveniência de 149 empreendedoras do Rio de Janeiro ${ }^{2}$, a supracitada autora constatou que, em geral, as empreendedoras são maduras e possuem comportamentos bastante ligados ao perfil empreendedor por essência, como destemo e autoconfiança. No entanto, a situação financeira é um motivo de parcimônia para as gestoras estudadas. Via de regra, possuem uma percepção de sucesso e vitória por sua trajetória e boa qualidade de vida. O espaço profissional e a vida pessoal relacionada a filhos são objetos de grande satisfação para essas empreendedoras.

As diferenças naturais, físicas e psicológicas verificadas nos gêneros impõem, certamente, um conjunto distinto de concepções, valores e crenças, peças estas que são chave na construção de estratégias dos gestores frente a seus negócios. Neste enfoque, Takahashi, Graeff e Teixeira (2006) realizaram um estudo de caso no segmento educacional de Curitiba, com 13 empresas escolhidas por critérios intencionais. Restou evidenciado que as empresas entrevistadas apresentavam muitas das características até aqui verificadas, com empreendedoras maduras à frente do negócio, tendo o empreendimento sido iniciado por meio de capital próprio, tendo como principal motivação a satisfação pessoal.

Quanto à estratégia, as autoras notaram a dificuldade de relacionar ambiente interno e externo, havendo um direcionamento aos pontos internos do negócio. Além disso, como características das empreendedoras femininas para planejar no segmento da educação, ficou proeminente a gestão mais direcionada a reforçar a sua identidade e menos voltada para estruturas organizacionais e modelos de negócios.

Novamente abordando aspectos das decisões e estratégias que envolvem as dissoluções de conflitos diários relativos à posição da empreendedora, Jonathan e Silva (2007) destacam que características específicas das empreendedoras são proeminentes, como a auto-organização do tempo, o estabelecimento de parcerias estratégicas de articulação entre as demandas e a realização de atividades de alívio às tensões (atividade física e viagens). Os principais conflitos verificados pelas autoras foram os que envolvem 0 ambiente de trabalho em sua complexidade e o ambiente de trabalho e a família.

Em trabalho sobre as respostas de empreendedoras do segmento de construção de Curitiba aos conflitos trabalho-família, Strobino e Teixeira (2014) demonstram que o conflito entre o tempo com a família e o tempo no trabalho é o principal gerador de tensão. Nesse cenário, as empreendedoras elegeram como principais tensões as brigas, o pouco suporte dos maridos e o estresse gerado por problemas financeiros, ocasionando, assim, falta de ânimo para gerir o negócio, desmotivação e mau humor no trato com a família. Considerações no mesmo sentido são feitas por Teixeira e Bomfim (2016) para empreendedoras de agências de viagens.

Um aspecto muito interessante abordado pela pesquisa de Peñazola, Diógenes e Sousa (2008)demonstra a motivação da escolha profissional de 370 estudantes do curso de administração de duas universidades do Ceará. $O$ estudo revela que grande parte das mulheres entrevistadas fez sua escolha profissional tendo como alvo o mercado de trabalho. Apenas $14,4 \%$ das entrevistadas sinalizaram interesse em montar 0 


\section{Juliana Soares da Silva, Michel Frank Sullivan dos Santos Tavares, Djanires Lageano Neto de Jesus, Higya Alessandra Merlin}

próprio negócio, diante de um percentual de $32,1 \%$ dos homens que manifestaram esse interesse em função da escolha profissional. A pesquisa também sugere que esses resultados podem ser atribuídos ao papel histórico da mulher no lar e aos conflitos, estes principalmente de tempo relacionados à família.

Propondo uma abordagem alternativa para a análise do processo de criação de empresas, Vale, Sefarim e Teodósio (2011) avançaram por meio do ambiente teórico da imersão e das redes sociais, calculando quatro indicadores a partir de um questionário aplicado a 178 empreendedores, sendo 64 mulheres. Alguns importantes resultados foram obtidos, como o fato de que $57 \%$ das empreendedoras já haviam atuado em outra empresa antes de ingressar no seu próprio negócio, e o fizeram principalmente por influência de outra pessoa e por conta do desemprego. Já para os homens, a verificação de uma oportunidade de mercado foi o principal motivo.

Além desses aspectos, a pesquisa sugere que a mulher busca mais apoio em laços próximos no momento de abertura de seu próprio negócio. Contudo, ao se tornarem mais fortalecidos, os negócios geridos por mulheres não têm uma diversificação e ampliação de suas conexões. Constatou-se, também, que a entrada em negócios devido a sucessões ou experiências familiares anteriores ocorre em maior número com mulheres do que com homens (VALE; SEFARIM; TEODÓSIO, 2011).

\section{Políticas e programas de apoio}

Nesse ínterim de desigualdade de gênero, principalmente no que tange ao mercado de trabalho, 0 movimento para mudar essa situação e atender às necessidades e demandas das mulheres em meio ao ambiente institucional iniciou-se no Brasil e no mundo a partir da década de 1980. Ao longo do tempo, evidenciou-se um processo de construção da institucionalização de propostas, criação de instâncias e de controle de políticas sociais.

O Programa de Desenvolvimento das Nações Unidas (PNUD), em reconhecimento à importância da igualdade de gênero, criou em 1984 o Fundo de Desenvolvimento das Nações Unidas para a Mulher (UNIFEM), com o objetivo de garantir a transversalidade de gênero. Isso foi reiterado na pauta de discussões da IV Conferência Mundial Sobre a Mulher, que ocorreu em 1995, e na Conferência Pequim + 5, realizada em 2000. Assim, foram formalizados para todos os países membros da ONU os objetivos de aplicar perspectivas de gênero sobre todos os padrões legais e sociais, bem como propor e monitorar políticas de desenvolvimento, pesquisa e planejamento (WEC, 2005).

No Brasil, foi criado em 1985 o primeiro marco institucional, o Conselho Nacional dos Direitos da Mulher, incorporado em 2003 à Secretaria de Políticas para as Mulheres (SPM). Tal secretaria configura-se como 0 principal agente articulador das atividades em prol das mulheres, envolvendo ações em âmbito federal, estadual e municipal (BRASIL, 2013).

Com o estabelecimento da SPM, foi realizada a primeira Conferência Nacional de Políticas para as Mulheres (CNPM), em julho de 2004. Desta conferência participaram 1.787 delegadas e mais de 120 mil mulheres, tendo início o diálogo que resultaria no Plano Nacional de Política para a Mulher (PNPM) (BRASIL, 2013).

De acordo com Zouain e Barone (2009), o PNPM foi, originalmente, composto por cinco eixos de trabalho, a saber: combate à violência contra a mulher, educação, autonomia econômica e igualdade de oportunidades no mundo do trabalho, saúde, direitos sexuais e direitos reprodutivos. Com a realização de novas conferências em 2007 e em 2011, deu-se o estabelecimento do III PNPM, que demandou maior inserção das temáticas de gênero sobre a pauta de trabalho do governo. Este é o último plano elaborado até o momento, tendo sido publicado de forma oficial um relatório de trabalho envolvendo o biênio 20132015 (BRASIL, 2013).

Segundo os mesmos autores, este plano está sob a égide da SPM. Porém, no intuito de avaliar e monitorar o cumprimento das metas e ações definidas no plano, bem como de promover a articulação entre os diferentes órgãos do governo, foi estabelecido, em 2005, o Comitê de Articulação e Monitoramento do 
PNPM.

Aos cinco eixos de trabalho constantes do primeiro plano foram incorporados mais cinco no III PNPM. São eles: o fortalecimento e participação das mulheres nos espaços de poder e decisão; o desenvolvimento sustentável com igualdade econômica e social; 0 direito à terra com igualdade para as mulheres do campo e da floresta, a cultura, esporte, comunicação e mídia; o enfrentamento do racismo, sexismo e lesbofobia; a igualdade para as mulheres jovens, idosas e mulheres com deficiência ${ }^{3}$.

A partir do PNPM, foram criados outros mecanismos ligados à SPM, que deliberam sobre a atenção às necessidades da mulher. Exemplos são a Central de Atendimento à Mulher, criada em 2005 para orientar as mulheres em situação de risco e violência e para informar os seus direitos, e a Política Nacional de Enfrentamento à Violência contra as Mulheres, que se propõe a reduzir os índices de violência contra as mulheres, proteger os seus direitos, promover a disseminação de atitudes igualitárias e prover serviços especializados para mulheres em situação de violência (BRASIL, 2011b).

Além desses mecanismos, foi criado o Pacto Nacional pelo Enfrentamento à Violência contra as Mulheres, que tem por base a política nacional acima citada (Brasil, 2011a). No mesmo sentido, instituiu-se o Programa Nacional Trabalho e Empreendedorismo da Mulher, originário do Programa Rio: trabalho e empreendedorismo da mulher (PRTEM). Quanto a este, foi criado em 2007, no intuito de ser um programa piloto, referência para os demais estados brasileiros no sentido de promover ações sobre autonomia e igualdade no mercado de trabalho, além de cidadania, atendendo, essencialmente, o público feminino que se encontra nas faixas de renda de pobreza e miséria (ZOUAIN; BARONE, 2009).

Uma iniciativa do Serviço Brasileiro de Apoio às Micro e Pequenas Empresas (SEBRAE), criou o Prêmio Mulher de Negócios, em parceria com a SPM, com a Federação das Associações de Mulheres de Negócios e Profissionais do Brasil (BPW). O prêmio conta com o apoio técnico da Fundação Nacional da Qualidade (FNQ) e tem como objetivo principal reconhecer o empreendedorismo feminino no Brasil.

No que se refere ao empreendedorismo no Brasil, ainda se percebe que a maior procura por órgãos de apoio, principalmente do Sistema "S", parte do sexo masculino. Cerca de $60 \%$ dos empreendedores que procuraram auxílio em 2016 eram do sexo masculino (GEM, 2017). Dentre os principais órgãos de apoio, destaque para o SEBRAE.

Na visão dos autores Zouain e Barone (2009, p. 251), que realizaram uma análise das políticas públicas brasileiras para as mulheres, alguns fatores indicam "[...] a existência de uma percepção naturalizada dos legisladores, com características modelares hegemônicas da visão masculina, ao lidarem no campo político com as desigualdades vivenciadas por essa parcela populacional". Dentre esses fatores, os autores citam a recente criação da SPM, à época com reduzido corpo técnico, a falta de recursos financeiros para as políticas voltadas para a mulher, que necessariamente precisariam atender todo o território nacional e, por fim, os indicadores econômicos e sociais que demonstraram uma situação desprivilegiada da mulher em relação à remuneração no trabalho e ao índice de pobreza. Um primeiro passo rumo a melhorias, segundo os autores, seria a reformulação de regras, normas e práticas vigentes.

\section{Tendências e rumos}

A análise de um conjunto de dados dispostos nesta seção propõe-se a sinalizar algumas tendências em relação à inserção feminina no mercado de trabalho e, principalmente, no empreendedorismo, de forma a destacar se esses pontos convergem ou não para alguns aspectos teóricos.

Conforme o Anuário das Mulheres Empreendedoras e Trabalhadoras em Micro e Pequenas Empresas (2014-2015), produzido pelo SEBRAE e pelo Departamento Intersindical de Estatística e Estudos Socioeconômicos (DIEESE), o número de empregadores segregados por sexo no Brasil apresentou evolução positiva. O total de empregadoras mulheres teve um crescimento de $23,54 \%$ entre 2003 e 2013 , totalizando um incremento de 198 mil novas mulheres gerando empregos.

A participação das mulheres como empreendedoras em micro e pequenas empresas ampliou-se de $25,3 \%$ 


\section{Juliana Soares da Silva, Michel Frank Sullivan dos Santos Tavares, Djanires Lageano Neto de Jesus, Higya Alessandra Merlin}

para $29,2 \%$ entre 2003 e 2013 , e de $21,2 \%$ para $26,1 \%$ nos demais portes de empreendimentos, de acordo com dados do mesmo estudo, que indicou, ainda, um crescimento da ordem de $7,7 \%$ a.a. para o número de empregos femininos no mercado de trabalho.

Sobre a participação da mulher no mercado de trabalho, um dado chama a atenção: a diferença entre 0 número de horas efetivamente trabalhadas entre homens e mulheres em sua ocupação principal vem reduzindo ao longo do tempo, se observados os dados trimestrais extraídos da PNAD contínua. Este dado revela, de acordo com o Gráfico 1, que os gêneros vêm se equiparando no número de horas destinadas ao trabalho fora da residência, seja ele formal ou não. É uma pena que não existam ainda estimativas que considerem o número de horas trabalhadas em serviços domésticos sem comercialização, ou seja, o tempo gasto para que se cuide da casa, pois, com estas estimativas, a mulher teria mais horas trabalhadas em suas ocupações em comparação aos homens.

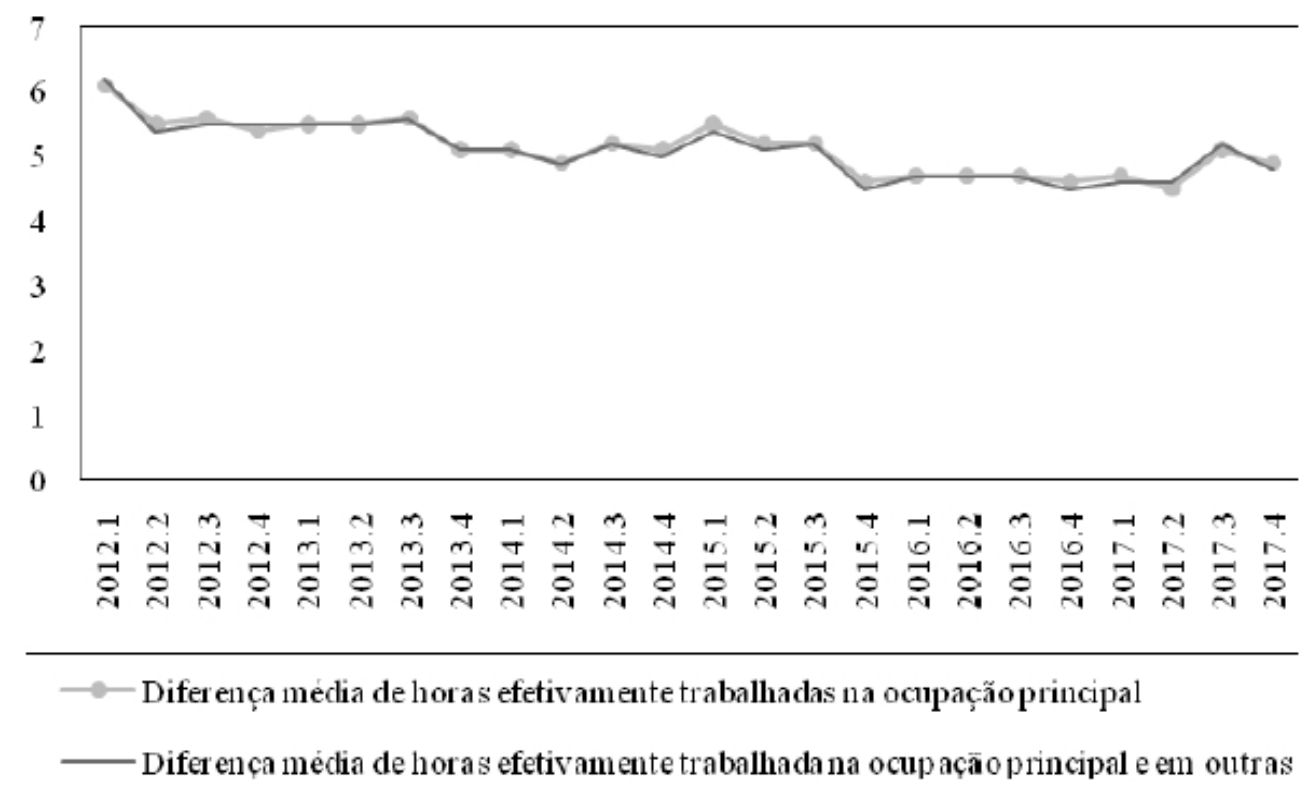

Gráfico 1 - Diferença média de horas efetivamente trabalhadas na semana de referência entre homens e mulheres para ocupação principal e demais ocupações.

Fonte: IBGE - PNAD Contínua Trimestral.

O dado apresentado no Gráfico 1 contrasta com os dados do Gráfico 2, que apresenta a diferença entre 0 rendimento médio dos homens e mulheres em sua ocupação principal e nas demais ocupações, sendo possível visualizar a tendência de crescimento da diferença entre esses rendimentos. Isso significa que, mesmo equiparando-se em número de horas formalmente trabalhadas, o rendimento das mulheres no mercado de trabalho brasileiro é menor do que o dos homens.

Este dado remete ao verificado na literatura por Machado, StCyr e Alves (2003) e Martinho (2012), quando ressaltam que a falta de satisfação com 0 trabalho exercido, as dificuldades relativas as condições de trabalho e o reflexo nos rendimentos tornam-se fatores motivadores para que as mulheres empreendam.

No entanto, essa motivação é fruto de um mercado díspar, que não considera parte significativa de sua força de trabalho e que deixa de ganhar em força econômica e em competitividade, conforme apontado pelo estudo do FEM (2005). Esta situação em torno dos rendimentos e das disparidades do mercado de trabalho também pode ser visualizada na América Latina, conforme os retratos apresentados pelos estudos da CEPAL (2013) e do Banco Mundial (2012). Pressupõe-se, assim, que poderíamos obter maior crescimento 
e redução das desigualdades de renda no caso de maior igualdade entre os gêneros.

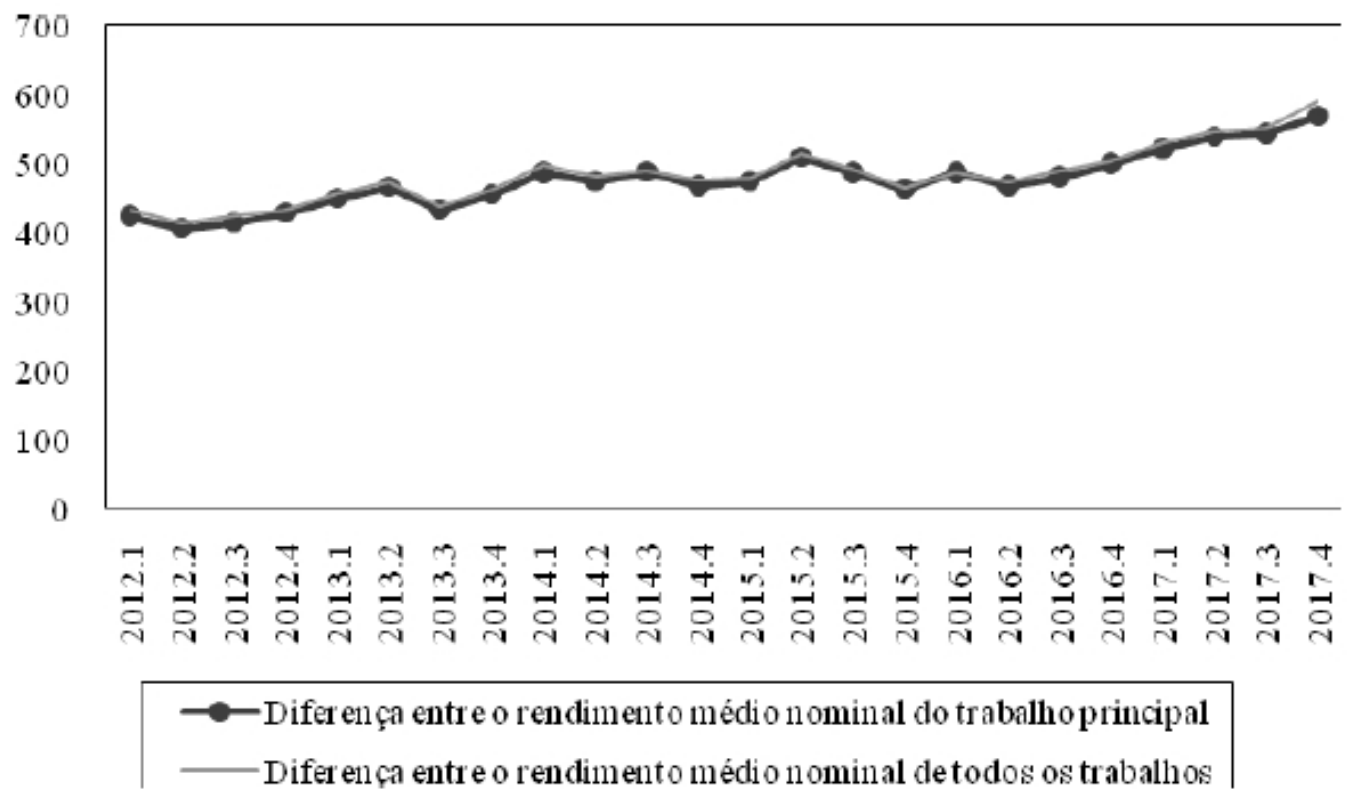

Gráfico 2: Diferença média entre o rendimento médio na semana de referência entre homens e mulheres para ocupação principal e demais ocupações.

Fonte: IBGE - PNAD Contínua Trimestral.

Esta temática traz à tona um debate cultural e estrutural da sociedade, com reflexos diretos na questão do empreendedorismo feminino. Ao que parece, as disparidades seguem ocorrendo no mercado de trabalho e têm impulsionado cada vez mais a projeção feminina. Isso pode ser evidenciado na busca da satisfação na gestão de seu próprio negócio e não mais em carreiras profissionais tradicionais. Considerações no mesmo sentido foram feitas por Takahashi, Graeff e Teixeira (2006), em um estudo de caso com o segmento educacional de Curitiba.

Outra evidência da temática pode ser verificada quando se observa a evolução do número de donos de negócios no Brasil, por gênero. O Gráfico 3 expõe que, das pessoas ocupadas, cerca de 16,2\% são homens donos de seus próprios negócios, e 7,3\% são mulheres. No entanto, verifica-se que o número de mulheres vem crescendo significativamente desde 2001 , quando a participação feminina era de $5,8 \%$, tendo chegado a 7,4\% em 2009, a maior na série apresentada. 


\section{Juliana Soares da Silva, Michel Frank Sullivan dos Santos Tavares, Djanires Lageano Neto de Jesus, Higya Alessandra Merlin}

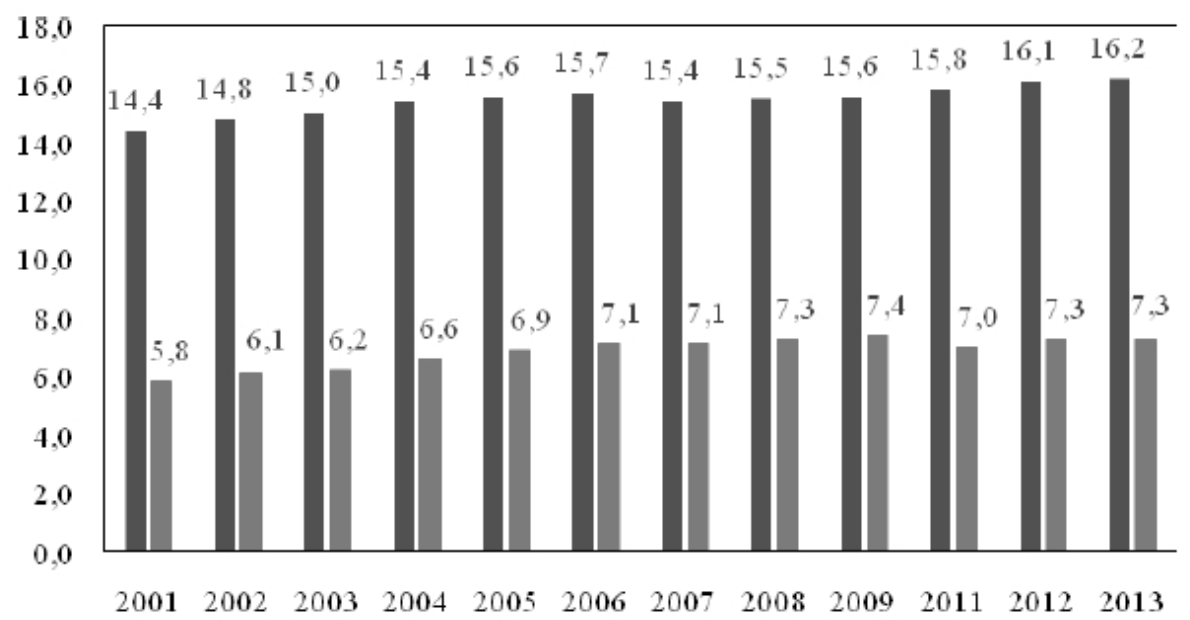

aHomens mulheres

Gráfico 3: Número de donos de negócios no Brasil, por gênero, em milhões de pessoas, de 2001 a 2013. Fonte: Elaboração própria a partir de dados do IBGE - PNAD com base no relatório do SEBRAE: Os donos do negócio no Brasil.

Outro dado que chama a atenção encontra-se na comparação entre homens e mulheres donos de seu próprio negócio quanto ao grau de instrução. As mulheres apresentam, em geral, melhor formação educacional do que os homens, consoante demonstrado no Gráfico 4. Este dado corrobora os perfis construídos nas contribuições teóricas recentes sobre o empreendedorismo feminino, como em Jonathan (2005), Takahashi, Graeff e Teixeira (2006)e Jonathan e Silva (2007), onde são evidenciadas empreendedoras maduras, com elevado nível de formação e tempo de experiência em seus segmentos. $A$ pesquisa do SEBRAE (2013), por usa vez, revela que 54\% das mulheres que são donas de negócios no Brasil possuem mais de cinco anos de experiência.

Essa demonstração traz à tona a percepção de efeito por parte das políticas que têm sido feitas no sentido de garantir o mesmo nível de acesso a homens. Todavia, somente a garantia de acesso não assegura igualdade, o que pode ser constatado nos números. As mulheres apresentam maior qualificação, boa experiência e perfil profissional maduro, mas seus rendimentos ainda são menores, como visto anteriormente e como pode ser reforçado pela informações do Gráfico 5, que expõe a distribuição de homens e mulheres por faixa de rendimento médio mensal, comparando os anos de 2011 e 2013.

Desta feita, vale uma reflexão sobre o papel das políticas públicas em relação ao ambiente favorável ao trabalho e ao empreendedorismo feminino. As posições de pouco destaque do Brasil nos índices globais de empreendedorismo feminino (GEl e FEI) possuem sinalizações neste sentido, onde o ambiente desfavorável faz com que o dilema das desigualdades se transfigure no fim do mês, no bolso das empreendedoras. Ademais, elas ainda enfrentam outras questões relacionadas ao dia a dia da gestão de seus negócios, conforme sinalizam as pesquisas de Salomão (2011) e Jonathan (2005). 


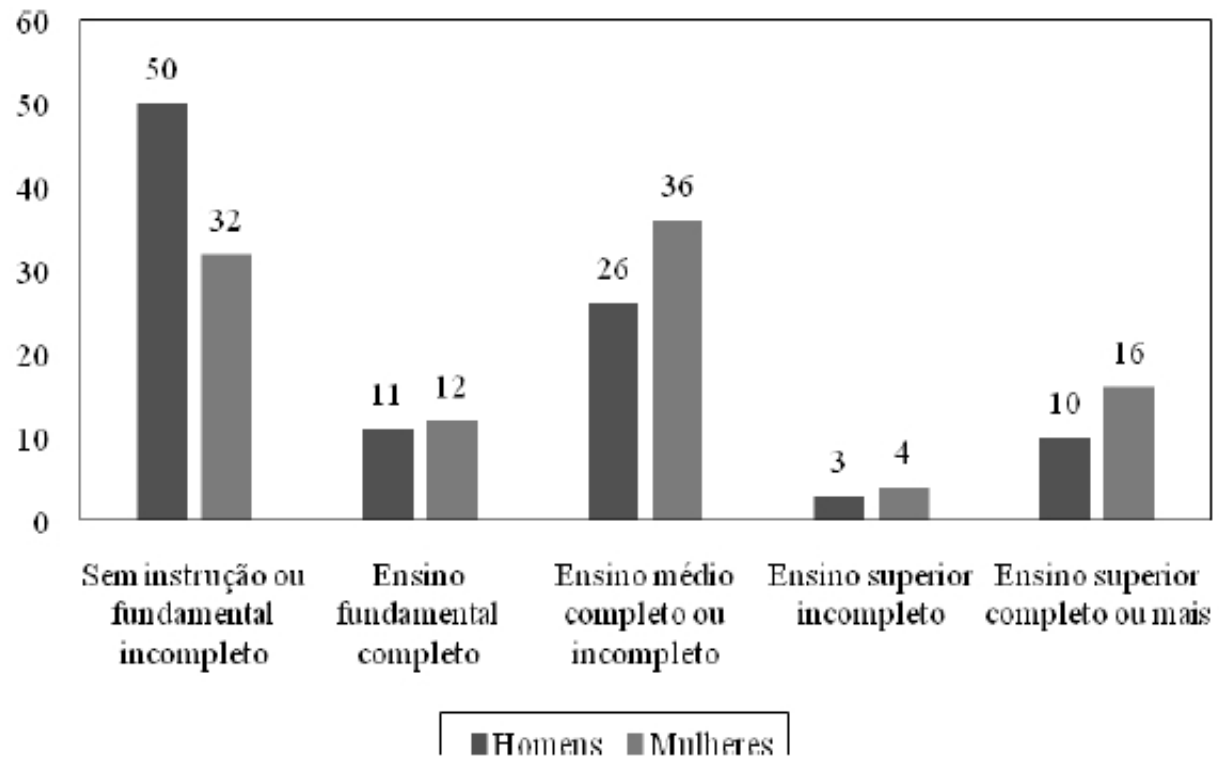

Gráfico 4: Distribuição dos donos de negócio no Brasil por grau deescolaridade,em valores \%, para 2013. Fonte: Elaboração própria a partir de dados do IBGE - PNAD com base no relatório do SEBRAE: Os donos do negócio no Brasil.

Pelo Gráfico 5, é possível identificar que um maior número de mulheres donas de seus próprios negócios recebe menos, considerando o número de salários mínimos, do que os homens também donos de seus próprios negócios. Além disso, verifica-se que, de 2011 para 2013, houve uma redução do número de mulheres que recebia mais de dois salários mínimos em 6 pontos percentuais. 0 maior número de donas de seu próprio negócio recebe até dois salários mínimos, o que não é um grande rendimento, mas que, certamente, está ligado a aspectos de satisfação e realização, conforme apresentado na teoria.

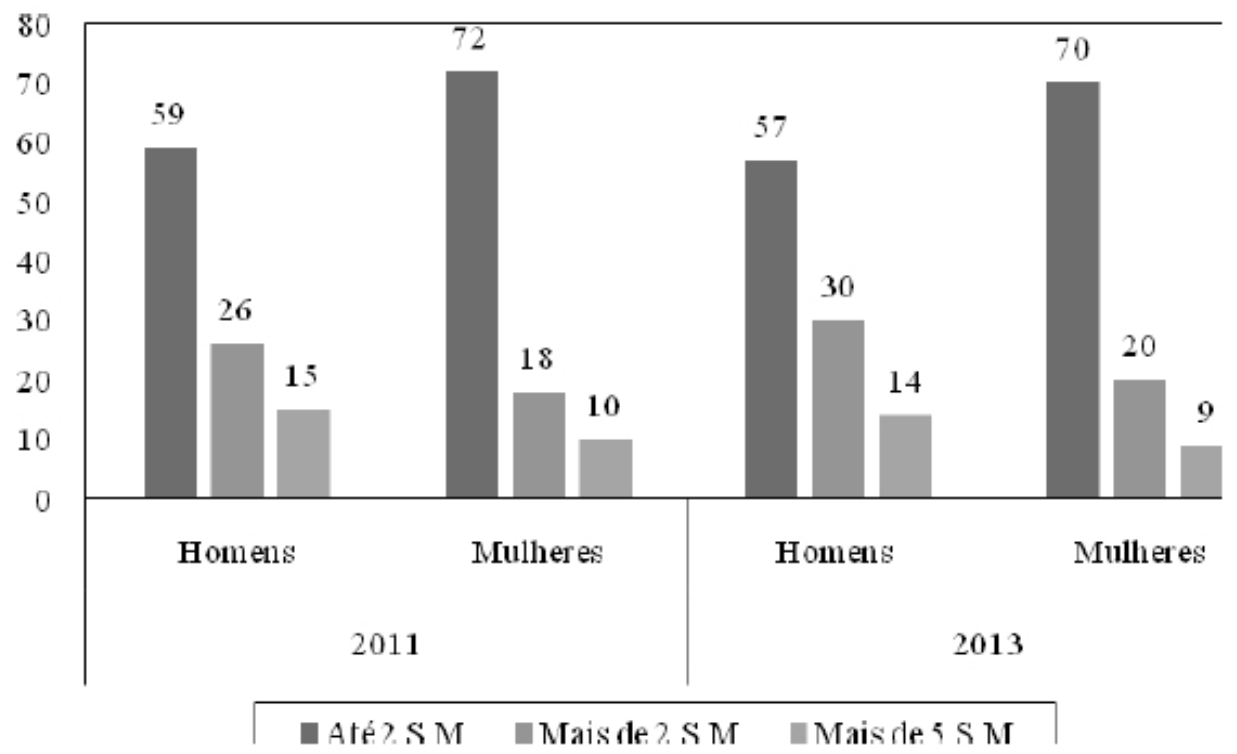

Gráfico 5: Distribuição por faixa de rendimento médio mensal,em valores \%, comparativo 2011 e 2013.

Fonte: Elaboração própria a partir de dados do IBGE - PNAD com base no relatório do SEBRAE: Os donos 
do negócio no Brasil.

A distribuição dos donos de negócios entre os setores econômicos, verificada no Gráfico 6, oferece algumas pistas que parecem contribuir na explicação dos resultados processados por Peñazola, Diógenes e Sousa (2008) e Vale, Sefarim e Teodósio (2011). 0 mesmo pode ser posto para as relações família-trabalho apresentadas por Strobino e Teixeira (2014) e Teixeira e Bomfim (2016). Nota-se que o setor de serviços é o que abriga o maior percentual de empreendedoras, saindo de 35\% do total em 2011 para 41\% em 2013.

As atividades em que as empreendedoras mais ingressam, ligadas ao comércio e serviços, são manicure e cabeleireira, bar e lanchonetes, ambulantes, acessórios e vestuário. São tipos de negócios que podem se processar com uma estrutura menos complexa, dependendo apenas da empreendedora. Em complemento, a margem de retorno é razoável, os custos são relativamente baixos e as atividades conferem uma certa flexibilidade, com possibilidade do trabalho em casa ou próximo dela.

A opção por este tipo de segmento também pode não estar diretamente relacionada à escolha profissional realizada a priori pela empreendedora, mas sim às relações que esta empreendedora tem mais próximas de si, como outras amigas ou parentes que obtêm bons ganhos e flexibilidade com esses tipos de serviços. No curso da carreira, quando a mulher está exercendo a escolha profissional no mercado de trabalho, depara-se com as distorções de rendimento verificadas em relação ao gênero masculino, optando, então, por ter outra forma de rendimento que não 0 antes escolhido como profissão, mas aquele que lhe é mais conveniente, oportuno e lhe parece possível.

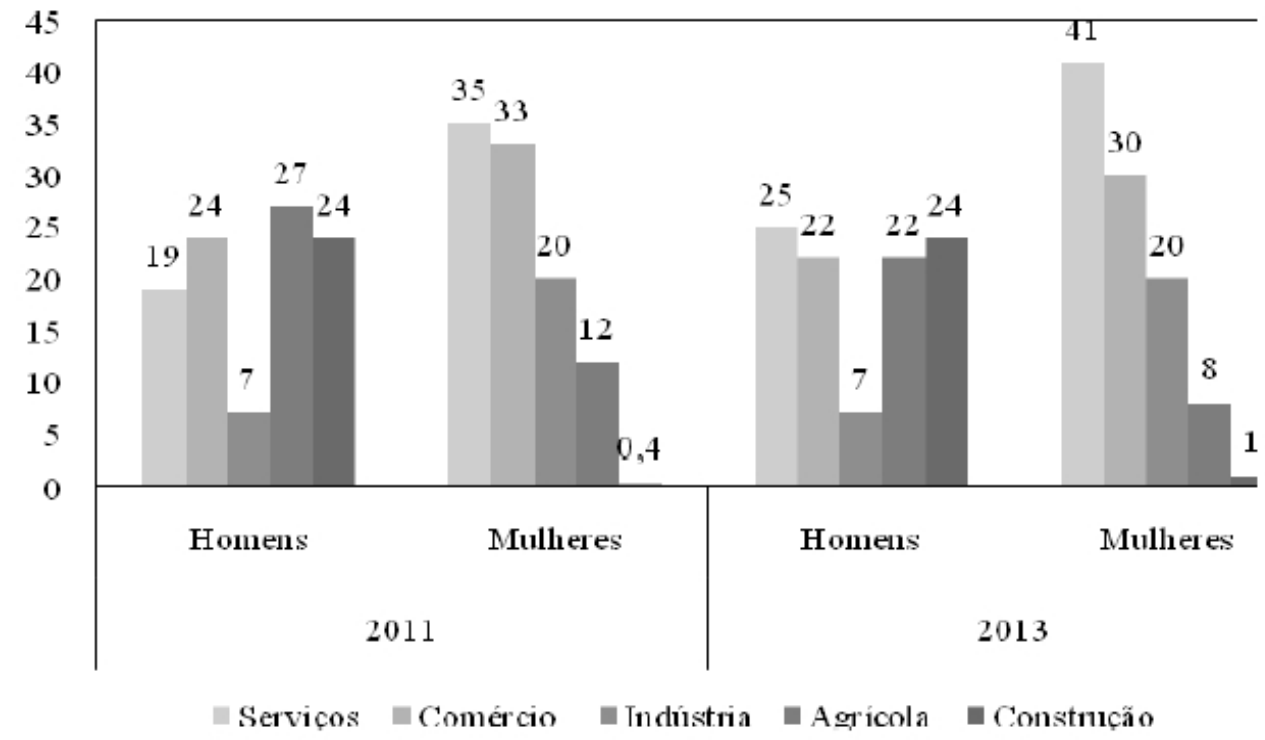

Gráfico 6: Distribuição dos donos de negócios no Brasil entre os setores econômicos,valoresem \%, comparativo 2011 e 2013.

Fonte: Elaboração própria a partir de dados do IBGE - PNAD com base no relatório do SEBRAE: Os donos do negócio no Brasil.

Essas conjecturas apresentadas fazem conexão com os resultados acima elencados. Por mais presuntivo que possa parecer, mostra-se aqui um modelo hipotético a ser comprovado por novos trabalhos embasados nas linhas teóricas e evidências até aqui oferecidas. A dinâmica de decisão da mulher entre empreender e o mercado de trabalho parece um tema muito sugestivo para que se avance nas pesquisas sobre 
empreendedorismo feminino. Nesse sentido, observa-se que ainda são poucas as iniciativas na literatura nacional. Apesar da alta qualidade, a quantidade de publicações é pequena.

A lógica que se estabelece nas subjetividades da escolha da mulher entre se lançar em uma atividade empreendedora, fazer uma opção pela família ou possuir uma carreira previamente eleita, ou tudo isso de uma só vez, pode ser a chave para a compreensão do avanço do empreendedorismo feminino frente às desigualdades sinalizadas pelo mercado e pela cultura "machista" estabelecida.

Ao analisar a distribuição das empreendedoras nos estados brasileiros, pela Figura 2, é possível constatar alguns pontos. A distribuição entre o número de donos de negócios apresenta considerável disparidade, porém não podem ser vistas expressivas diferenças entre gêneros na distribuição, o que permite inferir que as mulheres parecem estar distribuídas no mesmo padrão que os homens.

Os estados que apresentam as maiores concentrações de donos do gênero masculino são São Paulo e Minas Gerais. Para o gênero feminino, o destaque fica para São Paulo. Nota-se que as Regiões CentroOeste e Norte, bem como alguns estados da Região Nordeste, apresentam os menores números de empreendedores de ambos os gêneros.

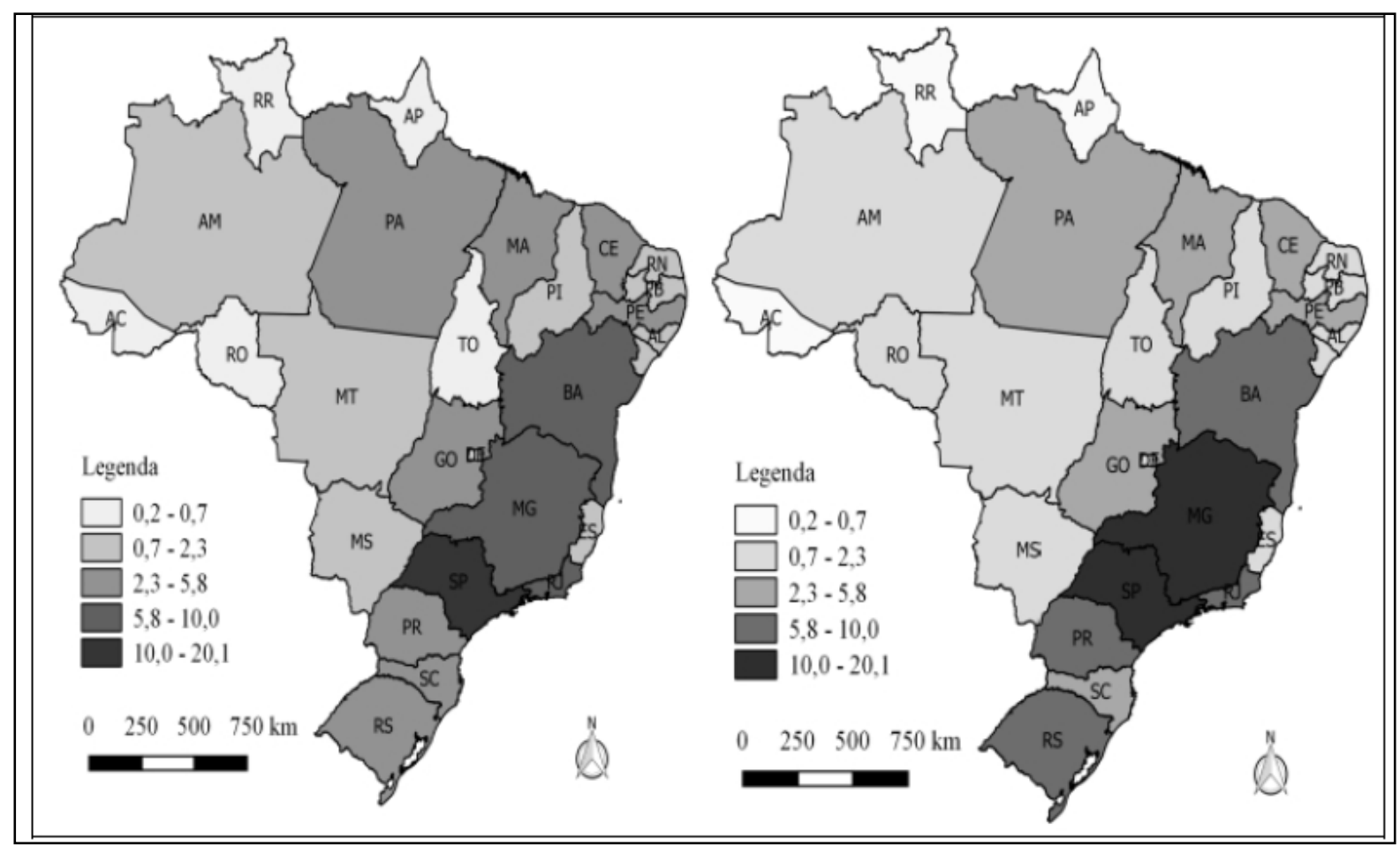

Figura 2 - Distribuição geográfica dos donos de negócios no Brasil, em \%, para 2013.

Fonte: Elaboração própria a partir de dados do IBGE - PNAD com base no relatório do SEBRAE: Os donos do negócio no Brasil.

As tendências aqui analisadas podem ser sumarizadas quanto à existência de um persistente avanço de inserção da mulher no ambiente de trabalho e no ambiente empreendedor, sendo evidente 0 aprofundamento deste processo nos anos em análise. Ao mesmo tempo, há uma desigualdade estrutural/cultural posta que desfavorece os ganhos da mulher no mercado de trabalho e enquanto empreendedora.

O movimento dinâmico de causa e efeito não é ainda bem descrito na literatura, no entanto, parece haver sentido nos apontamentos que descrevem como causa do aumento do empreendedorismo feminino as 


\section{Juliana Soares da Silva, Michel Frank Sullivan dos Santos Tavares, Djanires Lageano Neto de Jesus, Higya Alessandra Merlin}

desigualdades verificadas pelas mulheres no mercado de trabalho e as insatisfações com essas desigualdades. Existem respostas teóricas a serem respondidas quanto às dinâmicas de escolha das mulheres entre carreira no mercado de trabalho, casa e o empreendedorismo.

O setor em que as mulheres mais adentram como empreendedoras são os serviços e o comércio. Não parecem existir padrões de distribuição de empreendedores vinculados às características de gênero. As políticas públicas sugerem certo resultado ao garantir o acesso ao estudo para as mulheres. Entretanto, tais políticas podem ainda intensificar a atuação em relação ao ambiente empreendedor, para que, desde os seus estudos, as mulheres possam sentir-se motivadas a empreender, e não somente empreender por não ter outras opções.

\section{Conclusão}

O empreendedorismo feminino parece um grande oceano ainda a ser descoberto, principalmente no que concerne à evolução das pesquisas. Aspectos psicológicos e sócio-demográficos precisam ser explorados mais a fundo até que, de fato, confluam em perfis e características que possibilitem traçar a jornada das empreendedoras de forma prévia, compreendendo, assim, seus possíveis comportamentos.

Este estudo deteve-se em apresentar um pouco sobre o estado da arte do tema, a partir de pesquisas nacionais, configurando o sentido das contribuições teóricas, para, então, dar vida a essas proposições a partir de outros estudos a nível mundial e dados nacionais que fornecessem o rumo do empreendedorismo feminino no Brasil. As contribuições teóricas são relevantes e apontam, juntamente com os dados e demais estudos apresentados, que, em linhas gerais, existem grandes distorções no mercado de trabalho com relação ao gênero feminino. Essas distorções são oriundas de questões históricas e culturais, de forma que as políticas públicas ainda não deram conta de solucionar.

Neste movimento, as mulheres parecem ser empurradas a empreender pela necessidade que urge. No processo, deparam-se com conflitos e tensões, como a equalização trabalho-família, aspecto sobre o qual não tinham conhecimento prévio ao adentrarem ao empreendedorismo. Assim, empreender para o gênero feminino não é uma opção, mas uma questão de sobrevivência.

Contudo, as mulheres têm descoberto a realização e a possibilidade de conciliar seus quereres profissionais com a vida pessoal, rompendo com as desigualdades pregadas pelo mercado. As forças que fazem essas mulheres cumprirem tal feito devem, por oportuno, ser objeto de novos estudos. Nessa perspectiva científica, as contribuições podem delinear e expor esse quadro, além de servir como orientação para novas empreendedoras quanto aos desafios inerentes ao caminho a ser trilhado.

\section{Notas Explicativas}

${ }^{1}$ A autora utilizou para tais levantamentos os formatos de coletas de dados do inventário de David A. Kolb (LSI) e o questionário multifatores de liderança (MLQ), de Bernard Bass. Maiores detalhes sobre as categorias apresentadas podem ser obtidos no trabalho da autora.

${ }^{2}$ Por se tratar de uma pesquisa que visa a aspectos bastante psicológicos, fez-se uso de um instrumento de coleta de dados chamado inventário de qualidade de vida (QOLI) de Frisch (1992). Para mais informações, verificar a exposição do método da autora.

${ }^{3}$ Para mais detalhes sobre os objetivos, planos de ação e metas do III PNPM, consultar o relatório 20132015. 


\section{Referências}

ANDERSON, D. R.; SWEENEY, D. J. . W. T. A. Estatística aplicada a administração e a economia. Tradução de Luiz Sérgio de Castro Paiva. 2. ed. São Paulo: Pioneira, 2002.

BANCO MUNDIAL. The Effect of Women's Economic Power in Latin America and the Caribbean. BANCO MUNDIAL. [S.I.], 2012.

BRASIL, PRESIDÊNCIA DA REPÚBLICA. SECRETARIA DE POLITICA PARA AS MULHERES. Pacto Nacional pelo Enfrentamento à Violência contra as Mulheres. Brasilia, 2011a.

BRASIL, PRESIDÊNCIA DA REPÚBLICA. SECRETARIA DE POLÍTICA PARA AS MULHERES. Política Nacional de Enfrentamento à Violência contra as Mulheres. Brasilia, 2011b.

BRASIL. PRESIDÊNCIA DA REPÚBLICA. SECRETARIA DE POLÍTICA PARA AS MULHERES. Plano Nacional de Políticas para as Mulheres. Brasília, 2013.

CEPAL - COMISSÃO ECONÔMICA PARA A AMÉRICA LATINA E O CARIBE. Mulheres na economia digital: superar o limiar da desigualdade. CEPAL. Santiago, 2013.

FRISCH, M. B. Test manual and treatment guide for quality of life inventory. [S.I.]: Person, 1992.

GEDI - GLOBAL ENTREPRENEURSHIP AND DEVELOPMENT INSTITUTE. The Female Entrepreneurship Index (FEI). GEDI - Global Entrepreneurship and Development Institute. Washington, 2015.

GEM - GLOBAL ENTREPRENEURSHIP MONITOR. Empreendedorismo no Brasil - 2015. GEM. Curitiba, 2016.

GEM - GLOBAL ENTREPRENEURSHIP MONITOR. Empreendedorismo no Brasil - 2016. GEM. Curitiba, 2017.

GIL, A. C. Métodos e técnicas de pesquisa social. 6. ed. São Paulo: Atlas, 2008.

IBGE - INSTITUTO BRASILEIRO DE GEOGRAFIA E ESTATÍSTICA. Pesquisa Nacional por Amostra de Domicílios - PNAD. Disponivel em: <https://sidra.ibge.gov.br/home/cnt/brasil>. Acesso em: 21 jan. 2018.

JONATHAN, E. G. Mulheres empreendedoras: medos, conquistas e qualidade de vida. Psicologia em Estudo, Maringá, v. 10, n. 3, p. 373-382, set./dez. 2005.

JONATHAN, E. G.; SILVA, T. M. R. Empreendedorismo feminino: tcendo a trama de demandas conflitantes. Psicologia \& Sociedade, Florianópolis, v. 19, n. 1, p. 77-84, jan;/abr., 2007.

MACHADO, H. V.; ST-CYR, L. M. A.; ALVES, M. C. M. O processo de criação de empresas por mulheres. Revista de Administração de Empresas, São Paulo, v. 2, n. 2, jul./dez., 2003.

MALLON, M.; COHEN, L. Time for a Change? Women's Accounts of the Move from Organizational. British Journal of Management, v. 12, p. 217-230, 2001.

MARTINHO, S. I. P. Empreendedorismo Feminino: Motivações, características e obstáculos das mulheres empreendedoras em Portugal. Covilhã: Universidade da Beira Interior, Centro de Ciências Sociais e Humanas, 2012.

MARTINS, C. B.; CRNKOVIC, L. H.; PIZZINATTO, N. K.; MACCARI, E. A.Empreendedorismo feminino: características e perfil de de gestão em micro e pequenas empresas. São Paulo: XIII SEMEAD - Seminários em Administração, 2010.

PEÑAZOLA, V.; DIÓGENES, C. G.; SOUSA, S. J. A. Escolha profissional no curso de Administração: tendências empreendedoras e gênero. Revista de Administração Mackenzie, São Paulo, v. 9, n. 8, p. 151167, nov./dez., 2008. 
SALOMÃO, C. S. Mulheres empreendedoras em pequenas empresas: análise dos estilos de apredizagem e dos estilos de liderança. São Carlos: Escola de Engenharia de São Carlos da Universidade de São Paulo, 2011.

SEBRAE - SERVIÇO BRASILEIRO DE APOIO A MICRO E PEQUENAS EMPRESAS. Os Donos de Negócio no Brasil: análise por sexo. SEBRAE - SERVIÇO BRASILEIRO DE APOIO A MICRO E PEQUENAS EMPRESAS. Brasília, 2013.

SEBRAE - SERVIÇO BRASILEIRO DE APOIO A MICRO E PEQUENAS EMPRESAS. Anuário das mulheres empreendedoras e trabalhadoras em micro e pequenas empresas.

SEBRAE - SERVIÇO BRASILEIRO DE APOIO A MICRO E PEQUENAS EMPRESAS;

DIEESE - DEPARTAMENTO INTERSINDICAL DE ESTATÍSTICA E ESTUDOS SOCIOECONÔMICOS. São Paulo, 2015.

STILL, L.; TIMMS, W. Career barriers and the older woman manager. Women in Management Review, v. 13, n. 4, p. 143-155, 1998.

STROBINO, M. R. C.; TEIXEIRA, R. M. Empreendedorismo feminino e o conflito trabalho-família: estudo de multicasos no setor de comércio de material de construção da cidade de Curitiba. Revista de Administração, São Paulo, v. 49, n. 1, p. 59-76, jan./mar., 2014.

TAKAHASHI, A. R. W.; GRAEFF, J. F.; TEIXEIRA, R. M. Planejamento estratégico e gestão feminina em pequenas empresas: o caso das escolas particulares em Curitiba - Paraná. Organizações e Sociedade, Salvador, v. 13, n. 39, p. 29-44, out./dez., 2006.

TEIXEIRA, R. M.; BOMFIM, L. C. S. Empreendedorismo feminino e os desafios enfrentados pelas empreendedoras para conciliar os conflitos trabalho e família: estudo de casos múltiplos em agências de viagem. Revista Brasileira de Pesquisa em Turismo, São Paulo, v. 10, n. 1, p. 44-64, jan./abr., 2016.

VALE, G. M. V.; SEFARIM, A. C. F.; TEODÓSIO, A. S. S. Gênero, Imersão e Empreendedorismo: Sexo Frágil, Laços Fortes? Revista de Administração Contemporânea - ANPAD, Curitiba, v. 15, n. 4, p. 631649, jul./ago., 2011.

WORLD ECONOMIC FORUM. Empoderamento das Mulheres: Avaliação das Disparidades Globais de Gênero. Genebra, 2005.

ZOUAIN, D. M.; BARONE, F. M. Empreendedorismo feminino no Brasil: políticas públicas sob análise.

Revista de Administração Pública, v. 43, n. 1, p. 231-256, 2009. 